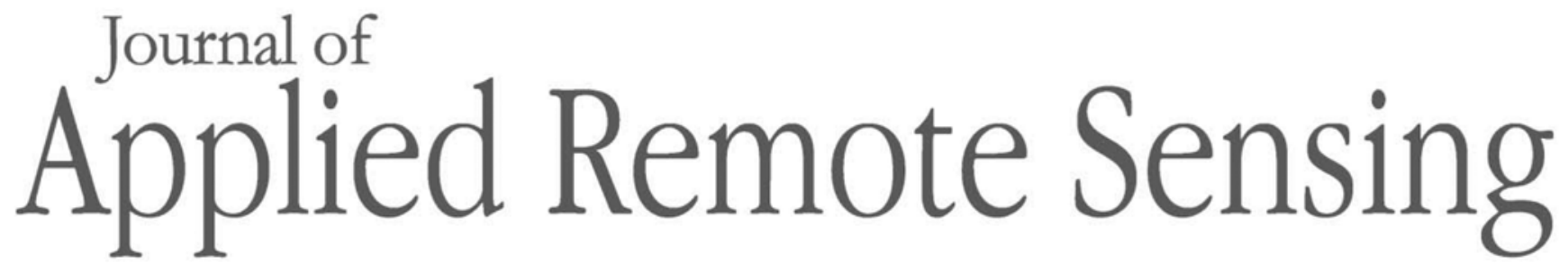

RemoteSensing.SPIEDigitalLibrary.org

\title{
Surface urban heat island effect and its relationship with urban expansion in Nanjing, China
}

Lili Tu

Zhihao Qin

Wenjuan Li

Jun Geng

Lechan Yang

Shuhe Zhao

Wenfeng Zhan

Fei Wang 


\title{
Surface urban heat island effect and its relationship with urban expansion in Nanjing, China
}

\author{
Lili Tu, ${ }^{\text {a }}$ Zhihao Qin, ${ }^{\text {, } *}$ Wenjuan Li, ${ }^{\mathrm{b}}$ Jun Geng, ${ }^{\mathrm{a}}$ Lechan Yang, ${ }^{\mathrm{a}}$ \\ Shuhe Zhao, ${ }^{a}$ Wenfeng Zhan, ${ }^{a}$ and Fei Wang ${ }^{\mathrm{a}}$ \\ ${ }^{a}$ Nanjing University, School of Geographic and Oceanographic Sciences, Nanjing 210093, China \\ ${ }^{\mathrm{b}}$ Chinese Academy of Agricultural Sciences, Institute of Agricultural Resources and \\ Regional Planning, Beijing 100081, China
}

\begin{abstract}
Nanjing, a typical megacity in eastern China, has undergone dramatic expansion during the past decade. The surface urban heat island (SUHI) effect is an important indicator of the environmental consequences of urbanization and has rapidly changed the dynamics of Nanjing. Accurate measurements of the effects and changes resulting from the SUHI effect may provide useful information for urban planning. Index, centroid transfer, and correlation analyses were conducted to measure the dynamics of the SUHI and elucidate the relationship between the SUHI and urban expansion in Nanjing over the past decade. Overall, the results indicated that (1) the region affected by the SUHI effect gradually expanded southward and eastward from 2000 to 2012; (2) the centroid of the SUHI moved gradually southeastward and then southward and southwestward, which is consistent with the movement of the urban centroid; (3) the trajectory of the level-3 SUHI centroid did not correspond with the urban mass or SUHI centroids during the study period and (4) the SUHI intensity and urban fractal characteristics were negatively correlated. In addition, we presented insights regarding the minimization of the SUHI effect in cities such as Nanjing, China. (C) The Authors. Published by SPIE under a Creative Commons Attribution 3.0 Unported License. Distribution or reproduction of this work in whole or in part requires full attribution of the original publication, including its DOI. [DOI: 10.1117/1.JRS.10.026037]
\end{abstract}

Keywords: surface urban heat island; urban expansion; centroid trajectory; fractal characteristics; Nanjing.

Paper 15838 received Dec. 4, 2015; accepted for publication May 25, 2016; published online Jun. 23, 2016.

\section{Introduction}

Rapid global urbanization has resulted in considerable environmental impacts. One major environmental consequence of urbanization, the urban heat island (UHI) effect, has been of concern since 1833, when Luke Howard proposed the concept of UHI based on the higher temperature in the center of London than in the suburbs. ${ }^{1}$ An improved understanding of the relationships between UHIs and urban expansion is essential for urban ecosystem studies and urban planning and management.

UHIs have commonly been understood as a phenomenon in which the land surface temperature (LST) or near-surface air temperature over urban regions is higher than that in the surrounding rural areas. ${ }^{2}$ In early studies, ${ }^{3-7}$ near-surface air temperature was commonly used to measure the UHI effect. With the development of thermal remote sensing, the LST retrieved from thermal remote sensing images has been used in many UHI studies. ${ }^{8-15}$ The annual temperature cycle model employed to analyze the temporal variation of the LST was derived from a time series of Landsat TIR data in Los Angeles from 2000 to $2010 .{ }^{16} \mathrm{Hu}$ and Brunsell ${ }^{17}$ studied long-term UHI effects using 2-, 4-, 8-, 16- and 32-day composite MODIS LST data from 2000 to 2010. Wu et al. ${ }^{18}$ used data from the newly launched HJ-1B satellite to monitor the UHI in Wuhan, China. These studies revealed that the LST retrieved from the thematic mapper (TM) and enhanced thematic mapper plus (ETM+) images has a higher spatial resolution, which is advantageous for revealing the spatial distribution features of the UHI.

*Address all correspondence to: Zhihao Qin, E-mail: zhihaoqin@163.com 
The surface urban heat island (SUHI) is the UHI indicated by the LST difference. ${ }^{2}$ The first SUHI observations by remote sensing were reported by Rao. ${ }^{19}$ Lazzarini et al ${ }^{20}$ studied the SUHI in desert city areas and calculated the value of the SUHI using the formula proposed by Voogt and Oke. ${ }^{2}$ Sobrino et al. ${ }^{21}$ evaluated the SUHI in the city of Madrid using the definition of SUHI proposed by Tiangco, Lagmay, and Argete. ${ }^{22}$ Because rural areas often have different types of land cover, $\mathrm{Jin}^{23}$ developed a new SUHI index in which the rural surface temperature was averaged from specific land cover in all rural pixels. Measuring the SUHI effect as the LST difference between the city and the surrounding region can accurately reflect the intensity of the SUHI phenomenon. Some studies have indicated that the UHI intensity may increase with increasing city size. ${ }^{24-26}$

The mechanism underlying UHIs is very complex. $\mathrm{Oke}^{27}$ proposed the following four significant controls on urban climate: urban structure, urban cover, urban fabric, and urban metabolism. These four factors are altered by urban expansion. Many researchers have studied the relationships between UHI (or LST) and urban expansion by using spatial analysis. Deosthali ${ }^{28}$ studied the impacts of rapid urban growth on heat and moisture islands in Pune city, India; Xiong et al. ${ }^{29}$ studied the impacts of rapid urbanization on the urban thermal environment of Guangzhou, South China; and Li et al..$^{30}$ characterized the spatiotemporal changes in the SUHI of Nanjing using Landsat thermal observations (eight scenes) from 1992 to 2011. However, few detailed studies of the spatiotemporal movement of the SUHI centroid and urban centroid have been conducted. Such movement may indicate the overall variations in the intensity and distribution of the SUHI and urban expansion.

Dramatic urban expansion has occurred universally in developing countries in recent decades. Nanjing is a typical large city in eastern China that has undergone dramatic expansion in the past decade because of regional economic growth and rapid urbanization. Consequently, several urban ecological environmental problems have appeared. ${ }^{31-33}$

The purpose of this study was to investigate the spatial and temporal variations of the SUHI and describe its relationship with the urban expansion in Nanjing for 2000 to 2012 by using LSTs derived from TM/ETM + thermal infrared data. Our intent is to provide insights related to improving the urban environment of Nanjing.

\section{Study Area and Data}

\subsection{Study Area}

Nanjing is the capital of Jiangsu Province and is located in the western Yangtze Delta, one of the most important industrial regions in China and the highest economic growth rate and population density in China. As one of three core cities in the Yangtze Delta and the second largest city in eastern China, Nanjing has undergone rapid urbanization since the $1980 \mathrm{~s} .{ }^{33}$ Rapid economic development and urbanization have attracted a large number of people to the city. By 2012, the GDP of Nanjing reached 720.1 billion yuan (US\$115.8 billion), and the urban population had increased to 4.6 million. The mean annual temperature in Nanjing is $15.4^{\circ} \mathrm{C}$, and the mean annual precipitation is $1106.5 \mathrm{~mm}$. The climate in Nanjing is characterized by a typical subtropical monsoon pattern with four clearly distinct seasons: a sunny spring, a hot and humid summer, a dry autumn, and a cold winter. Nanjing is one of China's notorious "four furnaces" (the other three are Wuhan, Chongqing, and Nanchang) in the Yangtze River Basin. Thus, Nanjing is a representative region for studying UHIs in China. Figure 1 shows the geographical location of the study area, which covers the urban center and the suburban (and rural areas) of Nanjing. The built-up region of Nanjing increased from $515 \mathrm{~km}^{2}$ in 2000 to $1311 \mathrm{~km}^{2}$ in 2012. The area of the region included in this study is $3340 \mathrm{~km}^{2}$. Thus, the built-up region of Nanjing city has experienced rapid expansion during the past decade, with an annual growth rate of $\sim 3 \%$. This expansion of the built-up region has exaggerated the SUHI effect in the city.

\subsection{Study Data}

Landsat TM images (row/path: 120/38) and ETM+ images from 2000 to 2012 were used in this research. The data were acquired during clear atmospheric conditions, and the images were 

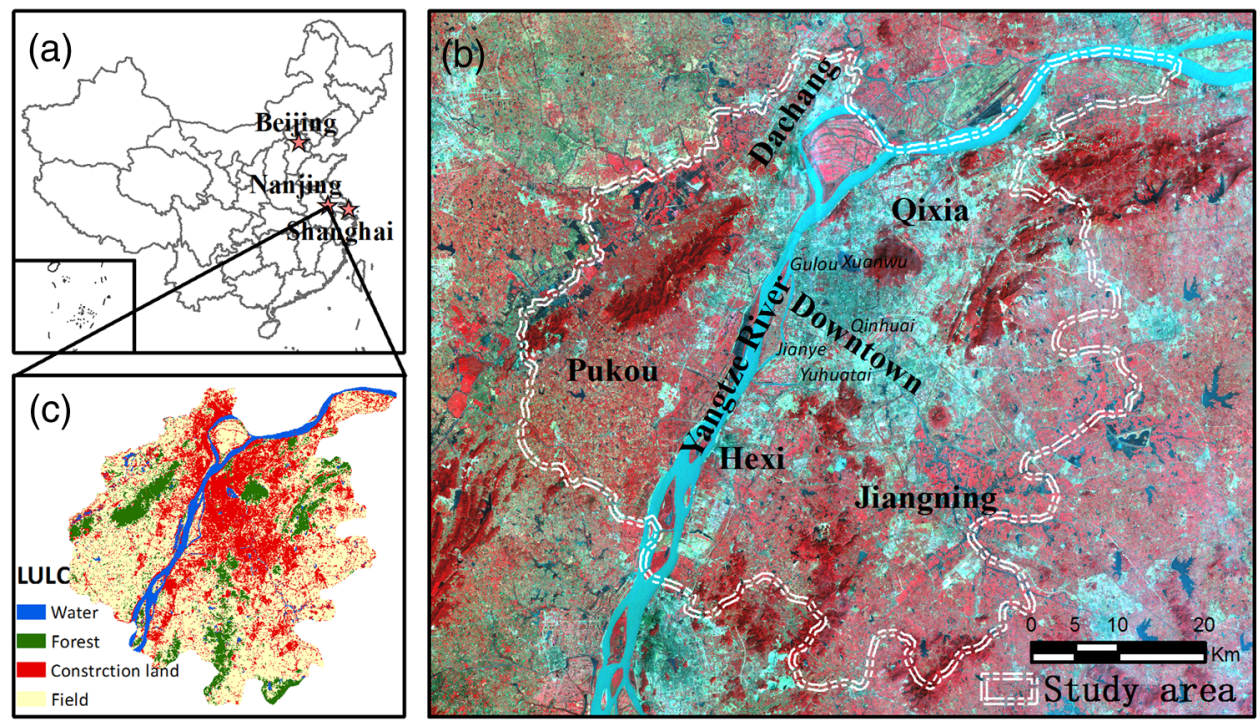

Fig. 1 (a) Geographical location of Nanjing, China; (b) Landsat TM image of the study area acquired on October 17, 2011, with a 432 RGB composite image; and (c) land use and land cover of the region on October 17, 2011.

obtained from the USGS Earth Resource Observation Systems Data Center, which corrected the radiometric and geometrical distortions of the images to a quality level of $1 \mathrm{G}$ before delivery. The Landsat images were further rectified to a common Universal Transverse Mercator coordinate system and were resampled using the nearest-neighbor algorithm with a pixel size of $30 \mathrm{~m} \times 30 \mathrm{~m}$ for all bands, including the thermal band. The images were obtained at approximately 10:30 am local standard time.

Landsat ETM+ images and Landsat TM images were selected to derive the LST. The higher resolution of these images allowed for more accurate temperature calculations and in-depth analysis. We used band 6 to calculate the LST based on a mono-window algorithm. LST is dependent on surface moisture conditions and, consequently, preceding precipitation. Zhou's ${ }^{34}$ study suggested that previous precipitation could mitigate the UHI intensity if it occurred

Table 1 Data used for the study area.

\begin{tabular}{|c|c|c|c|c|c|c|c|c|}
\hline \multirow{2}{*}{ Date } & \multirow{2}{*}{ ETM+ } & \multirow{2}{*}{ TM } & \multirow{2}{*}{$\begin{array}{l}\text { MOD } 05 \\
\text { MOD } 03\end{array}$} & \multirow{2}{*}{$\begin{array}{l}\text { Meteorological data; } \\
\text { Statistical data }\end{array}$} & \multicolumn{4}{|c|}{$\begin{array}{l}\text { Precipitation }(\mathrm{mm}) \text { on the days } \\
\text { before image acquisition }\end{array}$} \\
\hline & & & & & $1 \mathrm{DA}$ & 2DA & 3DA & 4DA \\
\hline 10/10/2000 & & $\bullet$ & $\bullet$ & $\bullet$ & 0 & 0 & 0 & 0.4 \\
\hline $10 / 24 / 2002$ & $\bullet$ & & $\bullet$ & $\bullet$ & 0 & 0 & 0 & 0 \\
\hline $10 / 19 / 2003$ & & $\bullet$ & $\bullet$ & $\bullet$ & 0 & 0 & 0 & 0 \\
\hline $10 / 21 / 2004$ & & $\bullet$ & $\bullet$ & $\bullet$ & 0 & 0 & 0 & 0.5 \\
\hline 10/16/2005 & $\bullet$ & & $\bullet$ & $\bullet$ & 0 & 0 & 0 & 0 \\
\hline 10/3/2009 & & $\bullet$ & $\bullet$ & $\bullet$ & 0 & 0 & 0 & 0 \\
\hline $10 / 17 / 2011$ & $\bullet$ & & $\bullet$ & $\bullet$ & 0 & 0 & 0 & 0 \\
\hline 10/19/2012 & $\bullet$ & & $\bullet$ & $\bullet$ & 0 & 0 & 0.4 & 4.4 \\
\hline
\end{tabular}

Note: Block dots indicate that the data were used. 1DA, 2DA, 3DA, and 4DA denote the precipitation amount on the first, second, third, and fourth day (from 20:00 pm on the previous day to 20:00 pm the next day) before the image was acquired (at approximately 10:30 am). For example, there was 0.4 mm rainfall on 4DA (from 20:00 pm on $10 / 06 / 2000$ to $20: 00$ pm on 10/07/2000) for image 10/10/2000. 
within the previous $72 \mathrm{~h}$. To minimize the impact of precipitation on UHI intensity, we selected images acquired after at least 2 days of no precipitation. Table 1 lists the precipitation data for each image, with 1DA, 2DA, 3DA, and 4DA denoting the precipitation amount on the first, second, third, and fourth day (from 20:00 pm on the previous day to 20:00 pm the next day) before the image was acquired (at approximately 10:30 am). As seen in Table 1, only one image (the last one) had a rainfall amount of $0.4 \mathrm{~mm}$ on the third day before its acquisition. The water vapor content was obtained from NASA (MOD05_L2), and Nanjing daily meteorological data were acquired from the China Meteorological Data Sharing Services System. ${ }^{35}$ These data were used as parameters in the algorithm used to estimate the LST from the Landsat images (Table 1).

\section{Methodology}

\subsection{Measuring the Intensity of the Surface Urban Heat Island Effect in Nanjing}

We used the following three indices to measure and comprehensively examine the spatiotemporal variations of the SUHI effect in Nanjing: the temperature difference index (TDI), the urban heat island effect classification index (HI), and the urban heat proportion index (UHPI).

\subsubsection{Temperature difference index}

Because the SUHI is defined as an environmental phenomenon in which the LST is higher in a city than in its surrounding region, this temperature difference has commonly been used to reflect the intensity of the SUHI effect as follows: ${ }^{2,22}$

$$
\mathrm{TDI}=\left(T_{\mathrm{c}}-T_{\mathrm{s}}\right),
$$

where TDI is the temperature difference index for the SUHI effect, $T_{\mathrm{c}}$ is the LST in the city, and $T_{\mathrm{s}}$ is the LST in the surrounding region.

\subsubsection{Urban heat island effect classification index}

The UHI is distributed heterogeneously in a city because of the inhomogeneous land surface, and the SUHI effect varies regionally. The area of the SUHI rapidly increases in some places and increases more slowly in other places. Additionally, the area of the SUHI effect decreases at some locations. We used the average temperatures of the built-up and suburban regions to reflect the internal changes of Nanjing's SUHI effect. The LST of the built-up region was based on the average temperature of the suburbs as follows: ${ }^{36}$

$$
\begin{aligned}
T_{\mathrm{c}} & \leq \bar{T}_{\mathrm{s}}, & & \text { HI-0, no SUHI effect region } \\
\bar{T}_{\mathrm{s}}<T_{\mathrm{c}} & \leq \bar{T}_{\mathrm{s}}+2.5, & & \text { HI-1, level-1 SUHI effect region } \\
\bar{T}_{\mathrm{s}}+2.5 & <T_{\mathrm{c}} \leq \bar{T}_{\mathrm{s}}+5, \text { and } & & \text { HI-2, level-2 SUHI effect region } \\
T_{\mathrm{c}} & >\bar{T}_{\mathrm{s}}+5, & & \text { HI-3, level-3 SUHI effect region }
\end{aligned}
$$

where $T_{\mathrm{c}}$ is the temperature in the built-up region and $\bar{T}_{\mathrm{s}}$ is the average temperature in the suburbs. By comparing $T_{\mathrm{c}}$ and $\bar{T}_{\mathrm{s}}$, we divided the built-up region into four categories: HI-0, HI-1, HI-2, and HI-3. HI-0 is a region with no SUHI effect, HI-1 is a region with a level-1 SUHI effect, HI-2 is a region with a level-2 SUHI effect, and HI-3 is a region with a level-3 SUHI effect. In this study, we identified the SUHI regions that met the HI-1, HI-2, or HI-3 criteria. The area of a 2.5-deg difference at 10:30 am would differ from the area at other times of the day. Analyses incorporating afternoon images would be valuable. However, afternoon images were not available for Landsat TM/ETM+, which has high spatial resolution necessary to capture the details on heterogeneity of the SUHI phenomenon in Nanjing. Although MODIS images might be an option for SUHI analysis, the spatial resolution of such images may be too low to distinguish the spatial heterogeneity of SUHI in the study region. ${ }^{37,38}$ 


\subsubsection{Urban heat proportion index}

The TDI reflects the general characteristics of the SUHI intensity, and the HI reflects the spatial variations of the SUHI. To comprehensively reflect the characteristics and the spatial differences of the heat island effect, an improved UHPI has been used widely to evaluate UHIs. ${ }^{29}$ The UHPI considers the proportions of the different classes in the SUHI region and expresses the SUHI intensity of the city as a whole. Generally, greater UHPIs correspond with stronger SUHI effects. The UHPI is defined as follows:

$$
\mathrm{UHPI}=\frac{1}{n} \sum_{i=1}^{k} w i \times p i
$$

where UHPI is the urban heat island proportion index, $n$ is the number of LST gradations in the built-up region, $k$ is the number of SUHI classes in the built-up region, and $p i$ is the area proportion of the $i$ 'th class in the built-up region. In addition, $w i$ is the weight of the $i$ 'th class and is equal to the number of the level. In this study, $n=4$ and $k=3$.

\subsection{Quantifying the Urban Expansion of a City}

The UHI effect is a phenomenon that exclusively occurs in cities and is closely related to urban expansion. Altering the surface properties will inevitably redistribute the incoming solar radiation and induce urban-rural contrast in the LST. ${ }^{39}$ Many studies of the relationships between the UHI and land use have been conducted..$^{20,21,29,40-43}$ To study how urban expansion influences the intensity and distribution of the SUHI, the urban area (UA), and the urban fractal dimensions were used to measure urban expansion.

\subsubsection{Urban area}

A supervised classification algorithm was applied to generate land cover maps from the images. The main classification features used in this study were the TM and ETM+ multispectral bands (bands 1 to 5 and band 7). The CART decision tree algorithm classification method was used, and the overall accuracy of the land cover maps was $>85 \%$, which was sufficient for extracting the built-up region. In this paper, we obtained the scope of the built-up region from the classification result assisted by visual interpretation. Next, we obtained the UA at different times during the study period.

\subsubsection{Fractal dimension}

A city is a complex, nonlinear area having fractal characteristics and internal organization. The space of a city is usually composed of many built-up regions. The size and form of each built-up region within the city may have important effects on the thermal environment of the city. The analysis of such effects is also important for understanding how the SUHI intensity changes with the evolution of city space. This is especially applicable to Nanjing, a city that developed along both sides of Yangtze River, leading to obvious fractal features in the organization of city space. According to the fractal theory of city space, ${ }^{44}$ a parameter, $U_{d}(t)$, was defined in this study to reflect the fractal dimension of Nanjing at year $t$. Following the studies of Shen ${ }^{45}$ and Ma et al., ${ }^{46}$ we estimated the parameter $U_{d}(t)$ as follows:

$$
\operatorname{LnUA}_{i}(t)=\frac{2}{U_{d}(t)} \operatorname{Ln} U P_{i}(t)+U_{c}(t),
$$

where $U A_{i}(t)$ is the area of the $i$ ' th built-up region in Nanjing in year $t, U P_{i}(t)$ is the perimeter of the $i$ 'th built-up region in Nanjing in year $t, U_{d}(t)$ and $U_{c}(t)$ are the fractal dimension and intercept in year $t$, respectively; and $L n$ denotes the natural logarithm. Thus, the fractal dimension and intercept were determined through regression to fit the area of built-up regions with the perimeter of the regions for each year under study. As Nanjing has grown very rapidly in recent decades, 
the fractal dimension may also change with the growth of the city. In general, a higher value of fractal dimension usually implies that the city has a relatively more complex shape of spatial organization. Because city expansion usually involves proportional increases in both the area and perimeter of build-up regions (in both size and number), we can logically expect that the fractal dimension of a city is a function of time. According to fractional theory of city space, if the fractal dimension of a city increases during a specific period, the area of the city would experience an external expansion in terms of growth pattern during this period. Conversely, a decrease in the fractal dimension usually implies that the area of the built-up region would increase as the gaps at the edges of the city are gradually filled in as a result of city growth. Both of these cases may have pronounced effects on the change of SUHI intensity of the city.

\subsection{Spatial Centroid Transfer Analysis}

To analyze the relationships between urban expansion and the changes in the SUHI more deeply, we drew the centroid transfer path for Nanjing city during the past decade. The spatial centroid is an important indicator that describes the spatial distribution of a geographic object and has often been used to study city evolution and changes in the SUHI. ${ }^{47,48}$ The spatial centroid is a comprehensive response to the SUHI and built-up region distribution characteristics. Analyzing the centroid transfer path not only reveals the spatial expansion of Nanjing but also illustrates the development of the city's effect on the development of the SUHI. Zhang et al. ${ }^{49}$ provided a theoretical definition and a formula for the spatial centroid for a single geographic object using vector landscape theory. To further analyze the shifts in the distance and direction of the centroid, Dong et al. ${ }^{50}$ used three variables: the spatial centroid coordinates, the shift distance, and the angle of the spatial centroid. The spatial centroid coordinates can be expressed as follows:

$$
X_{t}=\sum_{i=1}^{n}\left(C_{t i} \times X_{i}\right) / \sum_{i=1}^{n} C_{t i}
$$

and

$$
Y_{t}=\sum_{i=1}^{n}\left(C_{t i} \times Y_{i}\right) / \sum_{i=1}^{n} C_{t i}
$$

where $X_{t}$ and $Y_{t}$ are the mean spatial centroid coordinates of a geographic object; $C_{t i}$ is the area of portion $i$ of the object; and $X_{i}$ and $Y_{i}$ are the geometric centroids of the $i$ 'th portion. The shift distance and the shift angle of the spatial centroid are computed as follows:

$$
L_{t+1}=\sqrt{\left(X_{t+1}-X_{t}\right)^{2}+\left(Y_{t+1}-Y_{t}\right)^{2}}
$$

and

$$
\alpha_{t+1}=\left\{\begin{array}{l}
\arctan \left(\frac{Y_{t+1}-Y_{t}}{X_{t+1}-X_{t}}\right), X_{t+1} \geq X_{t} \\
\pi-\arctan \left(\frac{Y_{t+1}-Y_{t}}{X_{t+1}-X_{t}}\right), X_{t+1}<X_{t}
\end{array},\right.
$$

where $L_{t+1}$ is the shift distance of the spatial centroid from time $t$ to $t+1$ and $\alpha_{t+1}$ is the shift angle of the spatial centroid from time $t$ to $t+1$.

\subsection{Land Surface Temperature Retrieval from Enhanced Thematic Mapper Plus and Thematic Mapper Images}

High-spatial resolution LST estimates from Landsat ETM+ and TM were derived based on the mono-window algorithm developed by Qin et al. ${ }^{51}$ The algorithm was previously validated for various situations, which indicated that it provides an accurate LST estimate from Landsat images. ${ }^{52}$ Furthermore, the algorithm has been widely used for LST retrieval in previous SUHI studies. ${ }^{53-56}$ 
The mono-window algorithm can be summarized by the following equation:

$$
\mathrm{LST}=\left\{a \times(1-C-D)+[b \times(1-C-D)+C+D] \times T_{6}-D \times T_{a}\right\} / C,
$$

where $a=-67.355351 ; b=0.458606 ; T_{6}$ is the at-sensor brightness temperature $(\mathrm{K})$, which can be derived based on Planck's function; $T_{a}$ is the effective mean atmospheric temperature, which can be calculated using the near-surface air temperature $\left(T_{0}\right){ }^{51}$ and $C$ and $D$ are determined from the emissivity $\left(\varepsilon_{6}\right)$ and transmittance $\left(\tau_{6}\right)$ using the following formula:

$$
C=\varepsilon_{6} \times \tau_{6} ; D=\left(1-\tau_{6}\right)\left[1+\left(1-\varepsilon_{6}\right) \times \tau_{6}\right] .
$$

The emissivity can be estimated from the proportion of vegetation by using normalized difference vegetation index values. ${ }^{57,58}$ Atmospheric transmittance $\left(\tau_{6}\right)$ can be determined by constructing a linear regression model with the water vapor content. ${ }^{51}$ The water vapor content $\left(\mathrm{g} / \mathrm{cm}^{2}\right)$ was estimated from MODIS05_L2.

\subsection{Spatial Differentiation Analysis}

The study area was divided into several zones to analyze the spatial configuration of the SUHI effect region and the built-up region. Eight transects were drawn through the centroid of the city using the centroid of Nanjing in 2000 as the centroid of the NW profile $\left(22.5^{\circ}\right.$ to $67.5^{\circ}$ azimuth), and a new transect was constructed every $45 \mathrm{deg}$ (Fig. 2). Next, statistical analyses (supported by ArcGIS) were conducted to estimate the distribution of the SUHI and the built-up region in the different parts of Nanjing. Using this method, we analyzed the spatial distribution of various characteristics. Spatial differentiation analysis can help decision makers determine the cause of a SUHI, monitor SUHI development, and identify control measures for a comfortable city.

\section{Results and Discussion}

\subsection{Variability of the Surface Urban Heat Island Effect Intensity in Nanjing}

The statistics in Table 2 show the variability of the SUHI intensity in Nanjing during 2000 to 2012. An increasing trend of heat island intensity was observed in Nanjing during this period.

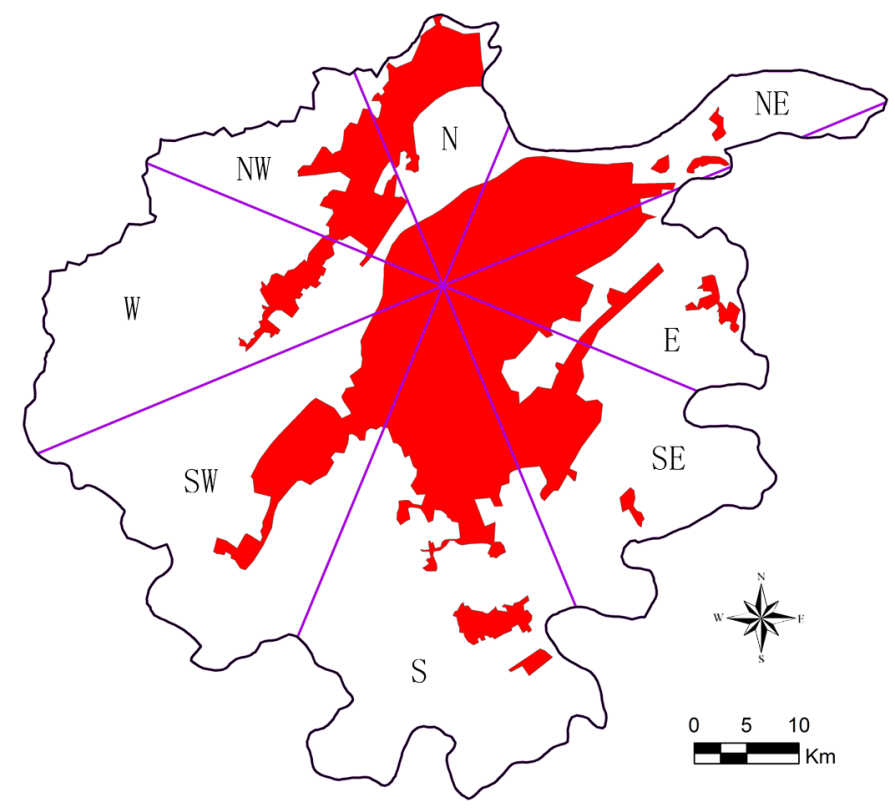

Fig. 2 Eight directions used to distinguish the spatial differentiation of urban expansion in Nanjing City (the red region is the built-up region in 2005). 
Tu et al.: Surface urban heat island effect and its relationship with urban expansion in Nanjing, China

Table 2 Variations of the SUHI from 2000 to 2012.

\begin{tabular}{lccccccccc}
\hline \hline & & 2000 & 2002 & 2003 & 2004 & 2005 & 2009 & 2011 & 2012 \\
\hline TDI $\left({ }^{\circ} \mathrm{C}\right)$ & & 2.18 & 1.05 & 1.84 & 1.58 & 1.96 & 2.47 & 2.25 & 2.93 \\
UHPI & & 0.32 & 0.22 & 0.28 & 0.27 & 0.30 & 0.37 & 0.35 & 0.40 \\
Areas of all HI classes $\left(\mathrm{km}^{2}\right)$ & $\mathrm{A}(\mathrm{HI}-0)$ & 61.4 & 123.8 & 64.2 & 85.7 & 111.5 & 67.9 & 121.3 & 133.2 \\
& $\mathrm{~A}(\mathrm{HI}-1)$ & 197.3 & 351.5 & 426.0 & 491.0 & 400.6 & 438.3 & 477.5 & 396.0 \\
& $\mathrm{~A}(\mathrm{HI}-2)$ & 188.7 & 69.3 & 165.6 & 159.6 & 268.5 & 417.0 & 397.6 & 453.1 \\
& $\mathrm{~A}(\mathrm{HI}-3)$ & 25.6 & 6.6 & 14.4 & 8.7 & 39.8 & 69.4 & 74.0 & 223.3 \\
& $\mathrm{~A}(\mathrm{HI}-1-\mathrm{HI}-3)$ & 411.6 & 427.5 & 606.0 & 659.3 & 708.9 & 924.6 & 949.1 & 1072.3 \\
& $\mathrm{P}(\mathrm{HI}-0)$ & 13.0 & 22.5 & 9.6 & 11.5 & 13.6 & 6.8 & 11.3 & 11.1 \\
Percentages of all HI classes the total (\%) & $\mathrm{P}(\mathrm{HI}-1)$ & 41.7 & 63.8 & 63.6 & 65.9 & 48.8 & 44.2 & 44.6 & 32.9 \\
& $\mathrm{P}(\mathrm{HI}-2)$ & 39.9 & 12.6 & 24.7 & 21.4 & 32.7 & 42.0 & 37.2 & 37.6 \\
& $\mathrm{P}(\mathrm{HI}-3)$ & 5.4 & 1.2 & 2.2 & 1.2 & 4.9 & 7.0 & 6.9 & 18.5 \\
& $\mathrm{P}(\mathrm{HI}-1-\mathrm{HI}-3)$ & 87.0 & 77.5 & 90.4 & 88.5 & 86.4 & 93.2 & 88.7 & 88.9 \\
\hline \hline
\end{tabular}

The TDI increased from 1.05 in 2001 to 2.93 in 2012. The UHPI increased to 0.4 in 2012 but was 0.3 in 2000 (Table 2). The area of the SUHI region was $411.6 \mathrm{~km}^{2}$ in 2000 and grew as the builtup region expanded. In 2012, the area of the SUHI region was $1072.3 \mathrm{~km}^{2}$. The percentage of the built-up region classified as the SUHI remained basically unchanged.

To analyze the spatial patterns of SUHI in Nanjing, the LST difference from the average LST in suburban regions was computed for each pixel of the built-up regions in Nanjing. According to the LST differences, we classified the pixels of the built-up regions into four categories: HI-0, HI-1, HI-2, and HI-3. Figure 3 shows the spatial distribution of the categories of SUHI effect level in Nanjing. We then extracted the area of each category and calculated its percentage of the total (Table 2). As seen from Fig. 3 and Table 2, the area of SUHI regions gradually increased with the expansion of built-up regions. However, the percentage of the built-up regions with heat island effects remained approximately stable (Table 2).

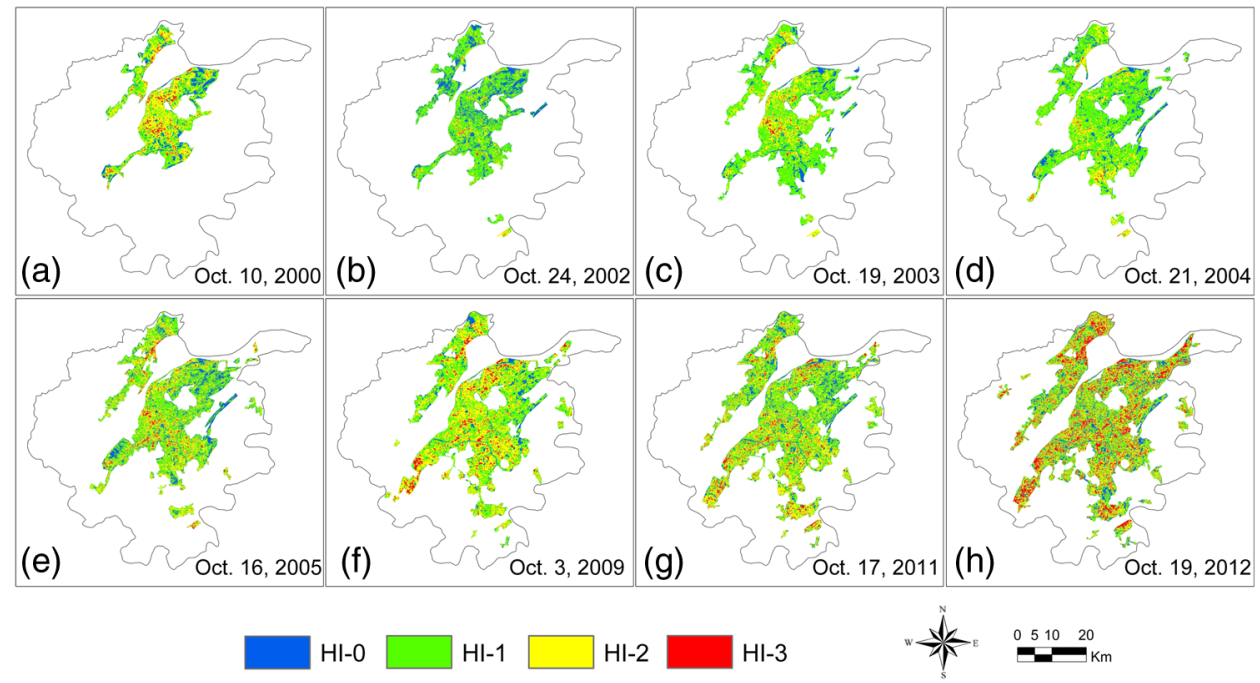

Fig. 3 Spatial distribution of the categories of SUHI effect level in Nanjing during various years: (a) October 10, 2000; (b) October 24, 2002; (c) October 19, 2003; (d) October 21, 2004; (e) October 16, 2005; (f) October 3, 2009; (g) October 17, 2011; and (h) October 19, 2012. 
After analyzing each of the SUHI regions, we determined that the area and percentage changes differed in each SUHI class (Table 2). The area of the high-grade SUHI effect regions (HI-2 and HI-3) gradually increased, whereas the area of the low-SUHI region (HI-1) remained stable. The percentage of the high-grade SUHI effect regions (HI-2 and HI-3) gradually increased, whereas the low SUHI region (HI-1) decreased. This pattern suggests that the conversion of low-level SUHI effect regions to high-level SUHI effect regions occurs frequently. Additionally, the increased SUHI area (particularly the HI-3 region) was not concentrated in the central portion of the city but was distributed on the edge of the built-up region, primarily because the amount of green space in the heart of the city increased and because more factories were located in the surrounding regions. In contrast with the SUHI region, several cooling spots and areas with no heat island effects (HI-0) were observed in the built-up region. These spots were mainly attributed to water bodies and green spaces (Fig. 3).

The distribution and growth of the SUHI regions also exhibited obvious spatial differences (Fig. 4). From 2000 to 2012, the area of the SUHI region increased mainly in the south,

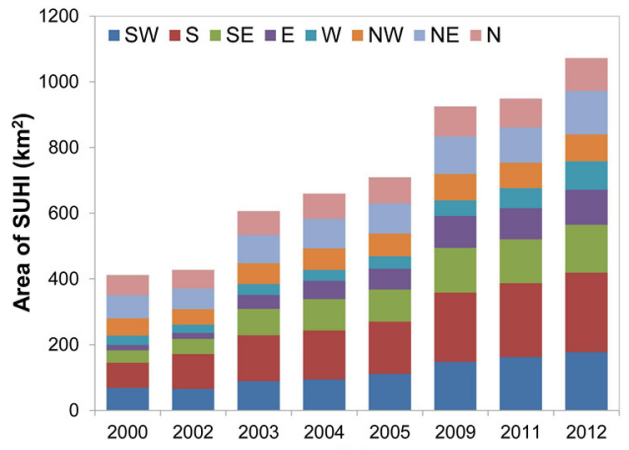

(a)

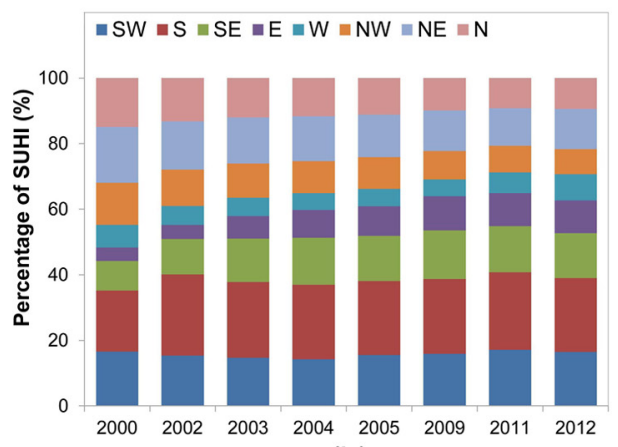

(b)

Fig. 4 Changes in the SUHI region in different directions in Nanjing during the past decade, including the (a) area and (b) percentage of the total.
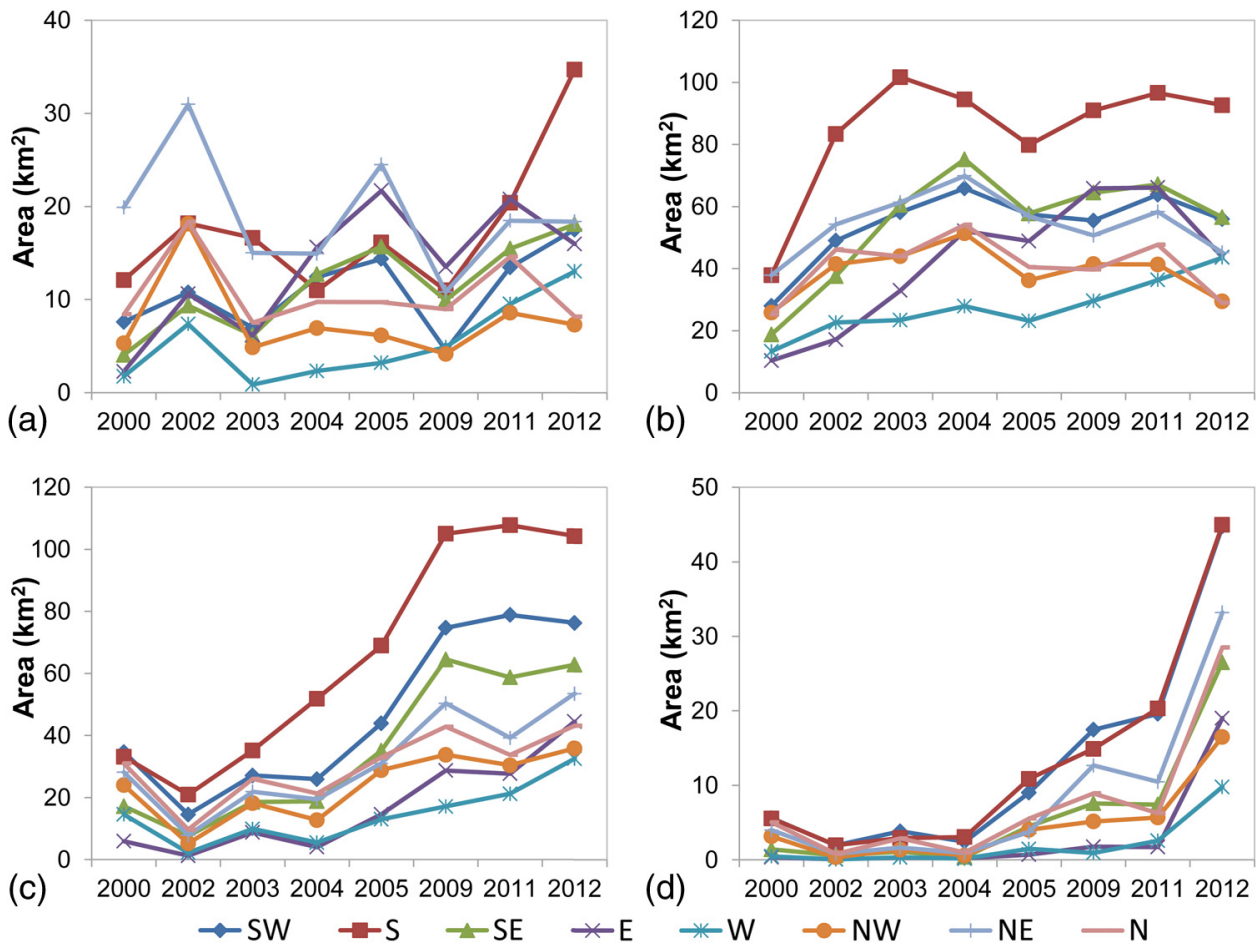

Fig. 5 Changes in the areas of the various SUHI classes in eight directions from Nanjing for (a) class $\mathrm{HI}-0$, (b) class $\mathrm{HI}-1$, (c) class $\mathrm{HI}-2$, and (d) class $\mathrm{HI}-3$. 

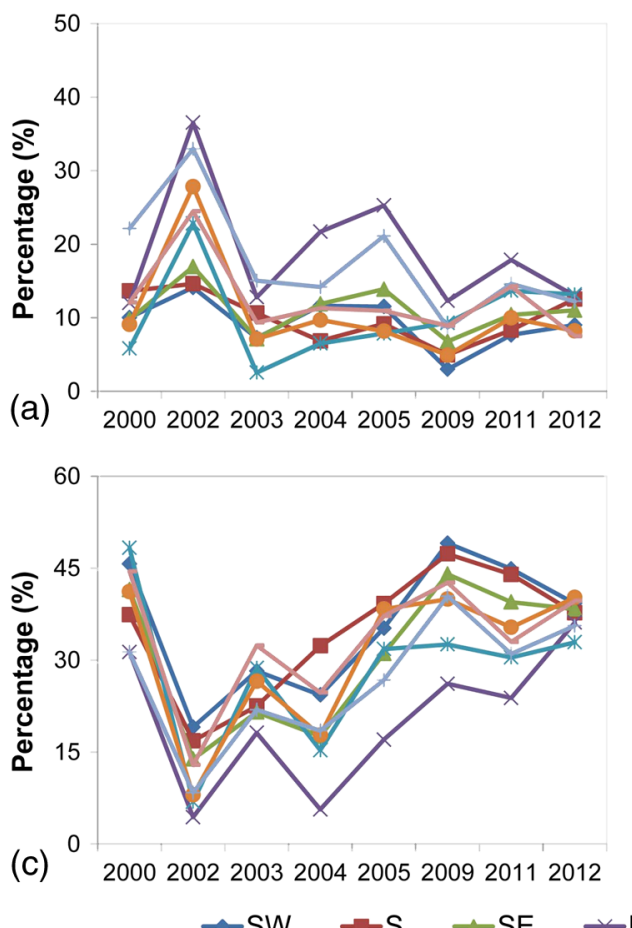
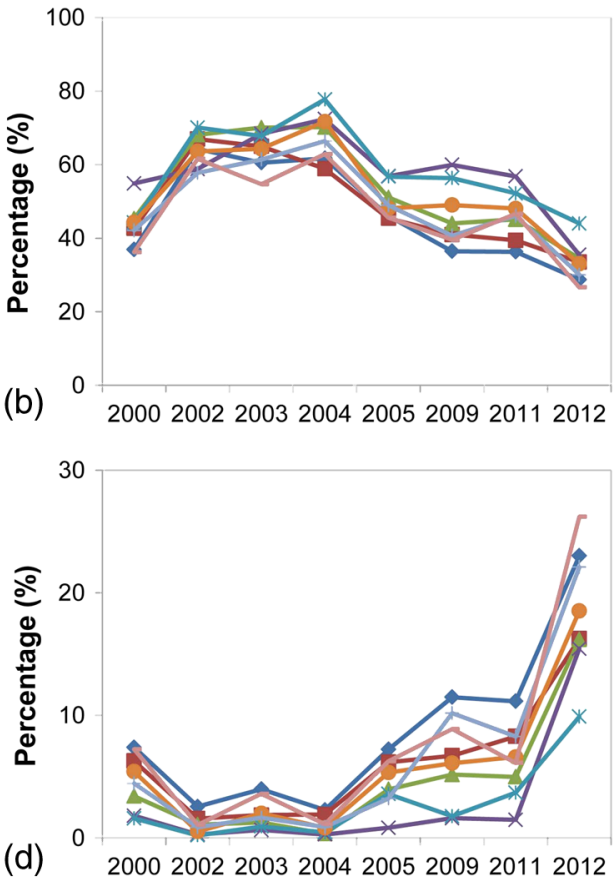

Fig. 6 Changes in percentages of the various SUHI classes in eight directions from Nanjing for (a) class $\mathrm{HI}-0$, (b) class $\mathrm{HI}-1$, (c) class $\mathrm{HI}-2$, and (d) class $\mathrm{HI}-3$.

southwest, and southeast, and relatively smaller increases were observed in the other five directions [Fig. 4(a)]. The percentages of the built-up region classified as SUHI significantly increased in nearly the same directions [Fig. 4(b)].

The changes in the area and area ratios of the different SUHI classes in the eight directional sections of Nanjing are shown in Figs. 5 and 6. The area of the higher-grade SUHI effect regions (HI-2 and HI-3) increased in the south and southwest [Figs. 5(c) and 5(d)]. The weak SUHI effect region (HI-1) and the region with no heat island effect (HI-0) also increased. In some directions, such as the northwest and north, the area of the weak SUHI effect decreased [Figs. 5(a) and 5(b)]. The proportion of the region with no HI effect (HI-0) remained nearly unchanged [Fig. 6(a)]. The area ratio of the weak HI effect region (HI-1) decreased in all directions [Fig. 6(b)]. The area ratios of the strong SUHI effect (HI-3) and medium SUHI effect (HI-2) regions increased noticeably, with slow growth rates in the east and west [Figs. 6(c) and 6(d)].

\subsection{Urban Expansion of Nanjing in the Past Decade}

Substantial changes have occurred in the built-up region of Nanjing during the past decade (Fig. 7). The area of the built-up region increased from $515.1 \mathrm{~km}^{2}$ in 2000 to $1311.1 \mathrm{~km}^{2}$ in 2012. Two major urban expansion periods occurred in 2002 and 2011, with urban expansions of 127.2 and $133.9 \mathrm{~km}^{2}$, respectively (Table 3). Figure 7 shows that the centroid of Nanjing began moving to the southeast in 2000. Until 2006, the transfer of the centroid point was toward the southwest. Simultaneously, Nanjing experienced rapid development in the southwest, and the fractal dimension of Nanjing increased from 1.23 in 2000 to 1.33 in 2007 (Table 3), indicating that Nanjing experienced external expansion between 2000 and 2007. For a few years, the fractal dimension remained low, which indicated that Nanjing's urban expansion primarily resulted from internal filling.

The urban expansion in Nanjing varied in different regions of the city (Fig. 8). In the past decade, Nanjing mainly expanded in the south, the southwest, the northeast, and the southeast [Fig. 8(a)]. In these directions, the area percentages were higher than those in other directions [Fig. 8(b)]. This result is related to the development strategies implemented in Nanjing. The south and southeast are composed of the Jiangning district, where a state-level economic 
Tu et al.: Surface urban heat island effect and its relationship with urban expansion in Nanjing, China

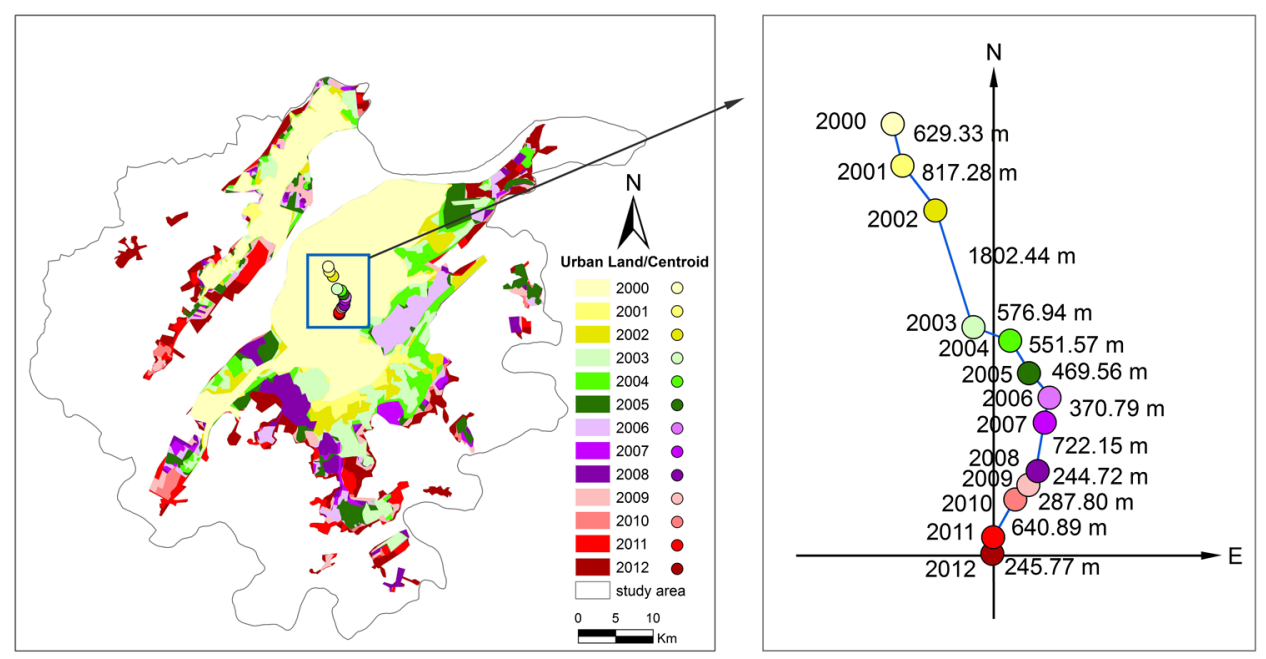

Fig. 7 Spatial expansion of the built-up region and changes in the urban centroid in Nanjing from 2000 to 2012.

Table 3 Urban expansion indices of Nanjing city from 2000 to 2012.

\begin{tabular}{lrllcccc}
\hline \hline & UA $\left(\mathrm{km}^{2}\right)$ & $\mathrm{UP}(\mathrm{km})$ & $\mathrm{U}_{d}$ & $X_{t}$ & $Y_{t}$ & $L(\mathrm{~m})$ & $\alpha$ \\
\hline 2000 & 515.07 & 257.51 & 1.23 & $118^{\circ} 46^{\prime} 59^{\prime \prime}$ & $32^{\circ} 04^{\prime} 18^{\prime \prime}$ & - & - \\
2001 & 539.90 & 296.13 & 1.25 & $118^{\circ} 47^{\prime} 05^{\prime \prime}$ & $32^{\circ} 03^{\prime} 59^{\prime \prime}$ & 629.33 & $283.32^{\circ}$ \\
2002 & 603.51 & 362.73 & 1.27 & $118^{\circ} 47^{\prime} 23^{\prime \prime}$ & $32^{\circ} 03^{\prime} 37^{\prime \prime}$ & 817.28 & $306.33^{\circ}$ \\
2003 & 730.69 & 455.52 & 1.30 & $118^{\circ} 47^{\prime} 43^{\prime \prime}$ & $32^{\circ} 02^{\prime} 41^{\prime \prime}$ & 1802.44 & $288.05^{\circ}$ \\
2004 & 808.66 & 402.26 & 1.27 & $118^{\circ} 48^{\prime} 04^{\prime \prime}$ & $32^{\circ} 02^{\prime} 34^{\prime \prime}$ & 576.94 & $339.75^{\circ}$ \\
2005 & 890.75 & 506.76 & 1.31 & $118^{\circ} 48^{\prime} 14^{\prime \prime}$ & $32^{\circ} 02^{\prime} 19^{\prime \prime}$ & 551.57 & $300.10^{\circ}$ \\
2006 & 958.21 & 504.02 & 1.28 & $118^{\circ} 48^{\prime} 25^{\prime \prime}$ & $32^{\circ} 02^{\prime} 07^{\prime \prime}$ & 469.56 & $309.90^{\circ}$ \\
2007 & 979.79 & 495.60 & 1.33 & $118^{\circ} 48^{\prime} 22^{\prime \prime}$ & $32^{\circ} 01^{\prime} 55^{\prime \prime}$ & 370.79 & $259.30^{\circ}$ \\
2008 & 1047.76 & 506.77 & 1.28 & $118^{\circ} 48^{\prime} 18^{\prime \prime}$ & $32^{\circ} 01^{\prime} 32^{\prime \prime}$ & 722.15 & $261.65^{\circ}$ \\
2009 & 1098.46 & 502.63 & 1.23 & $118^{\circ} 48^{\prime} 12^{\prime \prime}$ & $32^{\circ} 01^{\prime} 25^{\prime \prime}$ & 244.72 & $235.76^{\circ}$ \\
2010 & 1117.51 & 509.32 & 1.23 & $118^{\circ} 48^{\prime} 05^{\prime \prime}$ & $32^{\circ} 01^{\prime} 18^{\prime \prime}$ & 287.80 & $228.19^{\circ}$ \\
2011 & 1177.14 & 549.72 & 1.27 & $118^{\circ} 47^{\prime} 52^{\prime \prime}$ & $32^{\circ} 01^{\prime} 01^{\prime \prime}$ & 640.89 & $239.66^{\circ}$ \\
2012 & 1311.08 & 609.43 & 1.21 & $118^{\circ} 47^{\prime} 52^{\prime \prime}$ & $32^{\circ} 00^{\prime} 53^{\prime \prime}$ & 245.77 & $267.11^{\circ}$ \\
\hline \hline
\end{tabular}

and technological development zone is located. The northeast is the Qixia district, where a new university town is located. In the southwest, Hexi, a new city located in the Jianye district of Nanjing, has experienced rapid development, including the construction of the main stadium for the second Youth Olympic Games.

\subsection{Relationship between the Surface Urban Heat Island Effect and Urban Expansion}

Table 2 shows that the percentage of the SUHI in the built-up region remained relatively stable during urban expansion. Eight-direction segmentation analysis confirmed that the directions of the development of the SUHI region and the urban shift are identical. The trajectory of the SUHI 


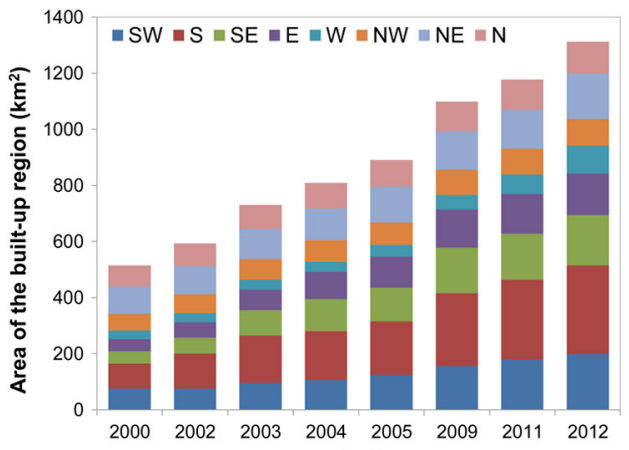

(a)

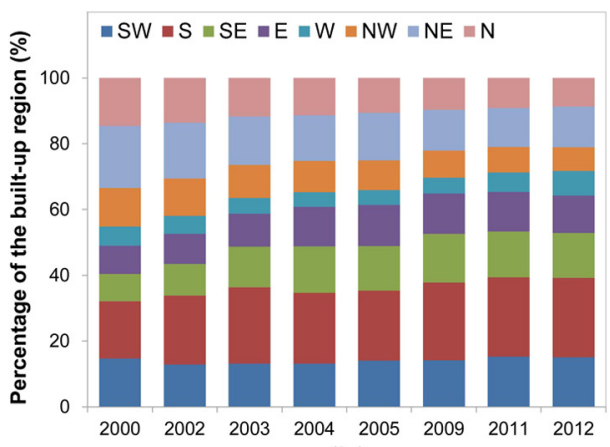

(b)

Fig. 8 Changes in the built-up regions in different directions from Nanjing during the past decade, including the (a) area and (b) percentage of the total.

centroid followed the route of the urban centroid movement (Fig. 9). The SUHI mirrored the urbanization of Nanjing and was closely related to the expansion patterns of the built-up region.

Another feature clearly evident in Fig. 9 is that the centroid movement route of HI-3, the most intense SUHI effect region, is inconsistent with the movement route of the SUHI centroid or the built-up region centroid. Because the function of different districts in a city would change during different periods (e.g., a residential area could become a commercial region during the period), the distribution of extreme high temperature (HI-3) is somewhat random, and the high temperature regions (HI-1 to HI-3) are concentrated in urban regions. Specifically, the internal structure of the city is very complicated, and the urban regions were divided into different function areas. Residential districts, parks, schools, and hospitals, which often have more green space, are located downtown. Factories and the airport, which have high heat storage capacities, are

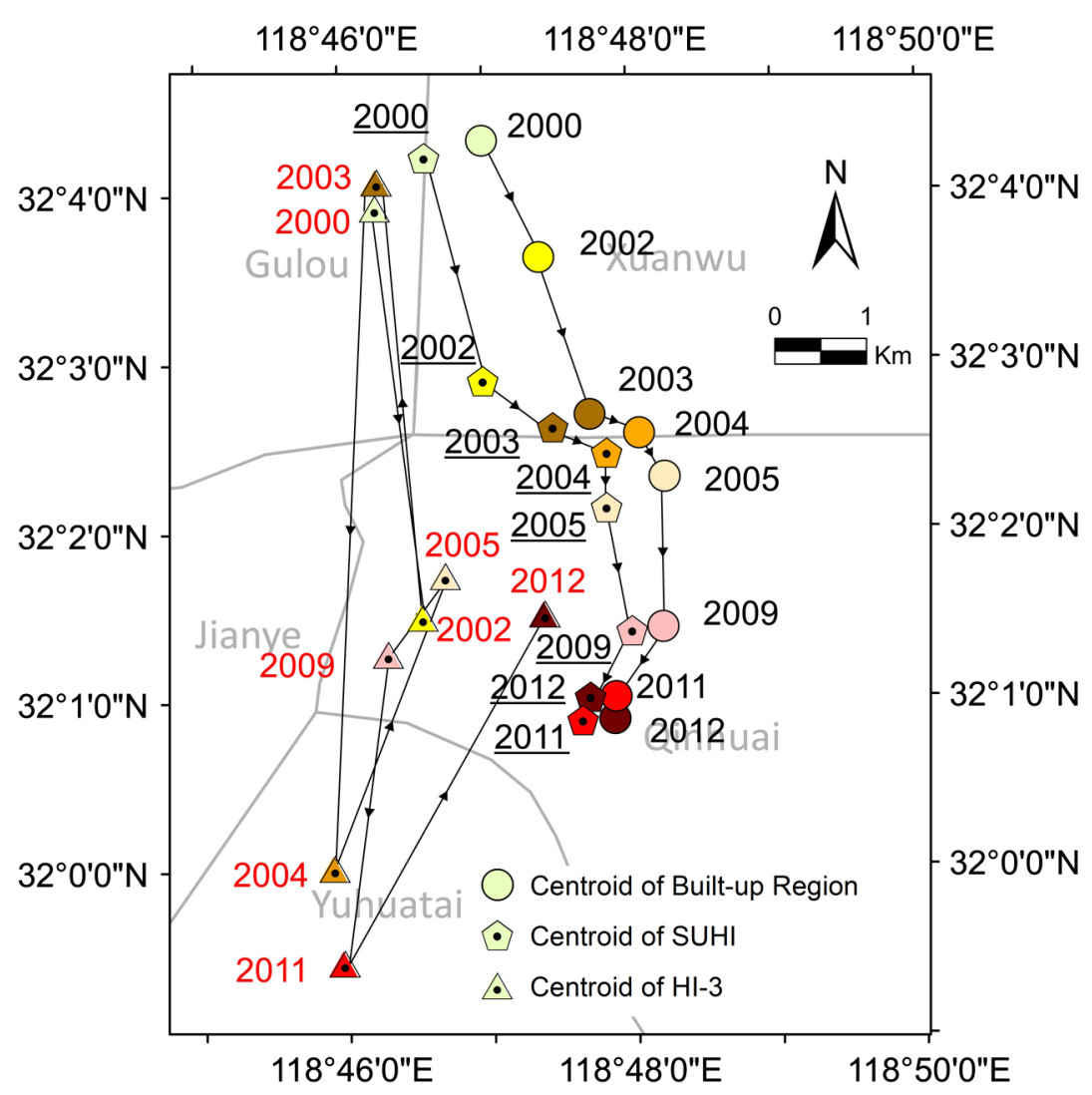

Fig. 9 Trajectories of the SUHI and urban centroids. 
distributed far from downtown. Other districts with high heat storage capacities are located downtown, such as the railway station and streets.

In general, the SUHI centroid moves gradually throughout the day. ${ }^{47}$ Usually, the city center may not be the hottest point in the morning because of the blockage of solar radiation from the deep street canyons in the city center. At this time, the SUHI tends to be stronger in areas with open impervious surfaces. However, in the afternoon and into the evening, the city center usually becomes the hottest spot due to the high solar angle in the afternoon, anthropogenic heat release, and small sky view factors (which reduce radiation cooling). In this study, the SUHI calculated from morning images may not have full capability to reflect the average daily condition of the SUHI in the city.

The area of HI-3 accounted for a small proportion of the total SUHI area (the highest percentage of HI-3 is $18.5 \%$ during the study period, which can be seen in Table 2), and so, the HI-3 centroids were pulled toward a specific spot when extremely high temperatures occurred in the region.

As shown in Table 2 and Fig. 6, HI-3 expanded much faster than HI-1 and HI-2. The area of HI-3 represented an increasingly larger proportion of the SUHI area during the study period. The distribution characteristics and formation mechanisms of HI-3 require further study.

To further understand the relationships between the spatiotemporal variations of the thermal environment and urban expansion, correlation analysis was conducted between the SUHI indices (TDI, UHPI, and the different $\mathrm{HI}$ classes) and the urban expansion indices (UA and $\mathrm{U}_{d}$ ). A summary of the correlations between the SUHI and urban expansion is given in Table 4. The SUHI indices and the urban expansion indices were correlated. Specifically, the TDI and UHPI were closely correlated with UA ( $R=0.73$ and 0.79 , respectively). With the increasing SUHI intensity and increasing UA during the study period, the HI-3 ratio and UA had the closest relative correlations, and the proportion of HI-1 exhibited a negative correlation.

In addition, the results in Table 4 show that the SUHI intensity was negatively correlated with the fractal dimension of the built-up region $(R=-0.59$ and -0.62 based on TDI and UHPI, respectively), which means that higher SUHI intensities correspond to smaller fractal dimensions (i.e., the urban regions are more concentrated). Thus, the SUHI intensity is stronger when the expansion of the built-up region is more compact, and the associated intensity is low when the urban region is not compact. The compact built-up region indicated that the area of the edge of the urban region was relatively small. The negative correlation could be explained by the fact that the compact built-up regions have less interaction with the cooler surrounding suburb regions than the built-up regions that are not compact. A case study of land use patterns and the SUHI in Berlin, Germany, also showed that the aggregation of corresponding industrial and commercial regions increases the LST. ${ }^{59}$ Our result is consistent with the findings of Schwarz and Manceur, who studied urban regions in Europe. ${ }^{60}$

The proportion of HI-1 in SUHI exhibited correlations with $\mathrm{U}_{d}$ and UA that were opposite of the correlations of HI-2 and HI-3 because the proportion of HI-1 decreased as the SUHI intensity increased. Due to the increased proportions of HI-2 and HI-3 and the decreased proportion of HI-1, HI-1 exhibited a development trend that was opposite of the overall SUHI, and HI-2 and HI-3 exhibited development trends that were consistent with the overall SUHI. HI-3 was more closely correlated with UA than HI-1, and HI-2 indicated that urban expansion did not simply lead to an increase in the SUHI intensity. More importantly, the proportion of higher-grade SUHI increased.

Based on the relationship between the SUHI and the urban expansion indices analyzed above, the following recommendations for mitigating the SUHI effects of Nanjing are proposed:

Table 4 Correlation coefficient of the SUHI index and urban expansion index.

\begin{tabular}{cccccc}
\hline \hline & TDI & UHPI & HI-1/SUHI & HI-2/SUHI & HI-3/SUHI \\
\hline UA & 0.73 & 0.79 & -0.60 & 0.52 & 0.74 \\
$\mathrm{U}_{d}$ & -0.59 & -0.62 & 0.65 & -0.50 & -0.66 \\
\hline \hline
\end{tabular}


1. Limit the increasing pace of new impervious surface construction and increase the area of naturally vegetated surfaces, such as urban parks, community gardens, and trees planted along roads.

2. Reduce the density of urban expansion instead of expanding around existing built-up regions.

3. City planning, particularly the positions of different functional areas, should be performed to adjust the urban thermal environment.

\section{Conclusions}

A thorough examination of the SUHI effect and its relationship with urban expansion in Nanjing, China, was conducted. Indices were used to effectively measure the intensity of the SUHI and examine the dynamics of its effects during the previous decade and its relationship with urban expansion in Nanjing. Landsat ETM + and TM images for eight representative periods (i.e., 2000, 2002, 2003, 2004, 2005, 2009, 2011, and 2012) were considered. The correlation of the SUHI effect with changes in the built-up region was analyzed to understand the dynamics of the SUHI effect intensity during the rapid physical expansion of the city.

Our results indicate that Nanjing experienced dramatic growth during the past decade. The physical expansion of the city, as indicated by the percentage of the built-up region, increased from $15.4 \%$ to $39.2 \%$. The area of the SUHI increased from $411.6 \mathrm{~km}^{2}$ in 2000 to $1072.3 \mathrm{~km}^{2}$ in 2012. The intensity of the SUHI increased in recent years, which was consistent with the physical expansion of the city.

Spatially, the main expansion of the SUHI region was in the south, southwest, southeast, and east directions. These directions are consistent with the directions of the development of the built-up region in Nanjing. The centroid of the SUHI tended to move gradually southeast (2000 to 2004) and then south (2004 to 2009) and southwest (2009 to 2012), following the movement of the urban centroid during the corresponding period.

Heat island classification analysis revealed that the yearly increase in the SUHI intensity resulted not only from temperature increases but also due to the area and the percentage of the high-temperature area (the HI-3) in the rapidly growing built-up regions. As the rapid growing of Nanjing into a metropolitan city, the functions of different urban districts within the city have changed at different stages during the period of recent decade. Moreover, our analysis of SUHI change in the city was based on morning images. The centroid movement routes of the most intensely affected SUHI region did not follow the movement of the SUHI centroid or the built-up region centroid.

The intensity of the SUHI was positively correlated with the urbanization level and negatively correlated with the fractal dimension of the built-up region, which implies that limiting the pace of impervious surface construction and reducing the density of urban expansion are important for minimizing the SUHI effect.

\section{Acknowledgments}

This study was supported by the National Natural Science Foundation of China (Grant No.: 41471300). We sincerely thank the websites http://www.usgs.gov/ and http://ladsweb. nascom.nasa.gov/ for providing the free remote sensing image data used in this study.

\section{References}

1. L. Howard, "The climate of London: deduced from meteorological observations, made in the metropolis and at various places around it," J. Harvey and Darton, Ed., Vol. 1, p. 348, London, United Kingdom (1833).

2. J. A. Voogt and T. R. Oke, "Thermal remote sensing of urban climates," Remote Sens. Environ. 86(3), 370-384 (2003).

3. K. Kłysik and K. Fortuniak, "Temporal and spatial characteristics of the urban heat island of Łódź, Poland," Atmos. Environ. 33(24), 3885-3895 (1999).

4. E. Jauregui, "Heat island development in Mexico City," Atmos. Environ. 31(22), 3821-3831 (1997). 
5. T. R. Oke, "The energetic basis of the urban heat island," Q. J. R. Meteorol. Soc. 108(455), $1-24$ (1982).

6. N. Tapper et al., "Modeling the winter urban heat island over Christchurch, New Zealand," J. Appl. Meteorol. 20(4), 365-376 (1981).

7. L. Huang et al., "A fieldwork study on the diurnal changes of urban microclimate in four types of ground cover and urban heat island of Nanjing, China," Build. Environ. 43(1), 7-17 (2008).

8. C. J. Tomlinson et al., "Derivation of Birmingham's summer surface urban heat island from MODIS satellite images," Int. J. Climatol. 32(2), 214-224 (2012).

9. J. P. Connors, C. S. Galletti, and W. T. L. Chow, "Landscape configuration and urban heat island effects: assessing the relationship between landscape characteristics and land surface temperature in Phoenix, Arizona," Landscape Ecol. 28(2), 271-283 (2012).

10. J. E. Nichol et al., "Urban heat island diagnosis using ASTER satellite images and 'in situ' air temperature," Atmos. Res. 94(2), 276-284 (2009).

11. J. Li et al., "Remote sensing evaluation of urban heat island and its spatial pattern of the Shanghai metropolitan area, China," Ecol. Complex. 6(4), 413-420 (2009).

12. R. Amiri et al., "Spatial-temporal dynamics of land surface temperature in relation to fractional vegetation cover and land use/cover in the Tabriz urban area, Iran," Remote Sens. Environ. 113(12), 2606-2617 (2009).

13. D. R. Streutker, "Satellite-measured growth of the urban heat island of Houston, Texas," Remote Sens. Environ. 85(3), 282-289 (2003).

14. D. R. Streutker, "A remote sensing study of the urban heat island of Houston, Texas," Int. J. Remote Sens. 23(13), 2595-2608 (2002).

15. C. P. Lo, D. A. Quattrochi, and J. C. Luvall, "Application of high-resolution thermal infrared remote sensing and GIS to assess the urban heat island effect," Int. J. Remote Sens. 18(2), 287-304 (1997).

16. Q. Weng and P. Fu, "Modeling annual parameters of clear-sky land surface temperature variations and evaluating the impact of cloud cover using time series of Landsat TIR data," Remote Sens. Environ. 140, 267-278 (2014).

17. L. Hu and N. A. Brunsell, "The impact of temporal aggregation of land surface temperature data for surface urban heat island (SUHI) monitoring," Remote Sens. Environ. 134, 162-174 (2013).

18. H. Wu et al., "Assessing the effects of land use spatial structure on urban heat islands using HJ-1B remote sensing imagery in Wuhan, China," Int. J. Appl. Earth Obs. 32, 67-78 (2014).

19. P. Rao, "Remote sensing of urban heat islands from an environmental satellite," $B r$. Am. Meteorol. Soc. 53(7), 647-648 (1972).

20. M. Lazzarini, P. R. Marpu, and H. Ghedira, "Temperature-land cover interactions: the inversion of urban heat island phenomenon in desert city areas," Remote Sens. Environ. 130, 136-152 (2013).

21. J. A. Sobrino et al., "Evaluation of the surface urban heat island effect in the city of Madrid by thermal remote sensing," Int. J. Remote Sens. 34(9-10), 3177-3192 (2013).

22. M. Tiangco, A. M. F. Lagmay, and J. Argete, "ASTER-based study of the night-time urban heat island effect in Metro Manila," Int. J. Remote Sens. 29(10), 2799-2818 (2008).

23. M. S. Jin, "Developing an index to measure urban heat island effect using satellite land skin temperature and land cover observations," J. Clim. 25(18), 6193-6201 (2012).

24. M. L. Imhoff et al., "Remote sensing of the urban heat island effect across biomes in the continental USA," Remote Sens. Environ. 114(3), 504-513 (2010).

25. A. J. Arnfield, "Two decades of urban climate research: a review of turbulence, exchanges of energy and water, and the urban heat island," Int. J. Climatol. 23(1), 1-26 (2003).

26. H.-S. Park, "Features of the heat island in Seoul and its surrounding cities," Atmos. Environ. 20(10), 1859-1866 (1986).

27. T. R. Oke, "Towards better scientific communication in urban climate," Theor. Appl. Climatol. 84(1-3), 179-190 (2006).

28. V. Deosthali, "Impact of rapid urban growth on heat and moisture islands in Pune city, India," Atmos. Environ. 34(17), 2745-2754 (2000). 
Tu et al.: Surface urban heat island effect and its relationship with urban expansion in Nanjing, China

29. Y. Xiong et al., "The impacts of rapid urbanization on the thermal environment: a remote sensing study of Guangzhou, South China," Remote Sens. 4(12), 2033-2056 (2012).

30. M. Li, L. Du, and W. Shen, "Spatio-temporal variations in urban heat islands effects of Nanjing, China derived from the dense Landsat imagery (1992-2011)," in 2012 5th Int. Congress on Image and Signal Processing, pp. 1104-1108, IEEE (2012).

31. D. Zhou et al., "Surface urban heat island in China's 32 major cities: spatial patterns and drivers," Remote Sens. Environ. 152, 51-61 (2014).

32. C.-S. Tang et al., "Urbanization effect on soil temperature in Nanjing, China," Energ. Build. 43(11), 3090-3098 (2011).

33. C. Xu et al., "Detecting the spatial differentiation in settlement change rates during rapid urbanization in the Nanjing metropolitan region, China," Environ. Monit. Assess. 171(1-4), 457-470 (2010).

34. J. Zhou et al., "Maximum nighttime urban heat island (UHI) intensity simulation by integrating remotely sensed data and meteorological observations," IEEE J. Sel. Top. Appl. Earth Obs. Remote Sens. 4(1), 138-146 (2011).

35. China Meteorological Data Sharing Services System, http://data.cma.cn

36. Y. Yang et al., "Spatial-temporal characteristics of urban heat island effect change of Nanjing city and its relation with land use change," Geogr. Res. 26, 877-886 (2007).

37. J. A. Sobrino et al., "Impact of spatial resolution and satellite overpass time on evaluation of the surface urban heat island effects," Remote Sens. Environ. 117, 50-56 (2012).

38. H. Guan et al., "Effective surface areas for optimal correlations between surface brightness and air temperatures in an urban environment," J. Appl. Remote Sens. 9(1), 096059-096059 (2015).

39. Q. Weng, "A remote sensing-GIS evaluation of urban expansion and its impact on surface temperature in the Zhujiang Delta, China," Int. J. Remote Sens. 22(10), 1999-2014 (2001).

40. B. Chun and J. M. Guldmann, "Spatial statistical analysis and simulation of the urban heat island in high-density central cities," Landscape Urban Plan. 125, 76-88 (2014).

41. Q. Weng, "Remote sensing of impervious surfaces in the urban areas: requirements, methods, and trends," Remote Sens. Environ. 117, 34-49 (2012).

42. J. Li et al., "Impacts of landscape structure on surface urban heat islands: a case study of Shanghai, China," Remote Sens. Environ. 115(12), 3249-3263 (2011).

43. A. M. Rizwan, L. Y. C. Dennis, and C. Liu, "A review on the generation, determination and mitigation of Urban Heat Island," J. Environ. Sci. 20(1), 120-128 (2008).

44. Y. Chen, "Fractal dimension evolution and spatial replacement dynamics of urban growth," Chaos Soliton. Fract. 45(2), 115-124 (2012).

45. G. Shen, "Fractal dimension and fractal growth of urbanized areas," Int. J. Geogr. Inf. Sci. 16(5), 419-437 (2002).

46. R. Ma et al., "Town and construction land growth of Changshu city," Acta Geogr. Sin. 3, 418-426 (2004).

47. J. Quan et al., "Multi-temporal trajectory of the urban heat island centroid in Beijing, China based on a Gaussian volume model," Remote Sens. Environ. 149, 33-46 (2014).

48. S. Carlesi et al., "Urban sprawl and land abandonment affect the functional response traits of maize weed communities in a heterogeneous landscape," Agric. Ecosyst. Environ. 166, 76-85 (2013).

49. S. Zhang et al., "Vector analysis theory on landscape pattern (VATLP)," Ecol. Model. 193(3-4), 492-502 (2006).

50. T. Dong, Q. Qin, and J. Wang, "Expansion modes of urban landuse in Mianyang City in the last 30 years," Geogr. Res. 30(4), 667-675 (2011).

51. Z. Qin, A. Karnieli, and P. Berliner, "A mono-window algorithm for retrieving land surface temperature from Landsat TM data and its application to the Israel-Egypt border region," Int. J. Remote Sens. 22(18), 3719-3746 (2001).

52. J. A. Sobrino, J. C. Jiménez-Muñoz, and L. Paolini, "Land surface temperature retrieval from LANDSAT TM 5," Remote Sens. Environ. 90(4), 434-440 (2004).

53. R. Pu et al., "Assessment of multi-resolution and multi-sensor data for urban surface temperature retrieval," Remote Sens. Environ. 104(2), 211-225 (2006). 
54. R. Okwen, R. Pu, and J. Cunningham, "Remote sensing of temperature variations around major power plants as point sources of heat," Int. J. Remote Sens. 32(13), 3791-3805 (2011).

55. C. Deng and C. Wu, "Examining the impacts of urban biophysical compositions on surface urban heat island: A spectral unmixing and thermal mixing approach," Remote Sens. Environ. 131, 262-274 (2013).

56. J. Pan, "Analysis of human factors on urban heat island and simulation of urban thermal environment in Lanzhou city, China," J. Appl. Remote Sens. 9(1), 095999-095999 (2015).

57. T. N. Carlson and D. A. Ripley, "On the relation between NDVI, fractional vegetation cover, and leaf area index," Remote Sens. Environ. 62(3), 241-252 (1997).

58. Z. Qin et al., "The estimation of land surface emissivity for Landsat TM6," Remote Sens. Land Resour. 3, 28-32 (2004).

59. P.-A. Dugord et al., "Land use patterns, temperature distribution, and potential heat stress risk-the case study Berlin, Germany," Comput. Environ. Urban Syst. 48, 86-98 (2014).

60. N. Schwarz and A. M. Manceur, "Analyzing the influence of urban forms on surface urban heat islands in Europe," J. Urban Plann. Dev. 141(3), A4014003 (2014).

Lili Tu is a PhD candidate in environmental remote sensing at Nanjing University, Nanjing, China, focusing on the application of thermal infrared remote sensing. During her postgraduate research, she studied the relationship between urban expansion and the urban thermal environment by using remote sensing and geographic information system technology.

Zhihao Qin is a professor affiliated to Chinese Academy of Agricultural Sciences in Beijing, China. Previously he also worked for Nanjing University, Nanjing, China. He got his $\mathrm{PhD}$ in remote sensing from Ben Gurion University of the Negev, Israel. Currently he is mainly doing researches on thermal remote sensing, agro-disaster monitoring with remote sensing, and agricultural development.

Wenjuan Li is a professor affiliated to Chinese Academy of Agricultural Sciences in Beijing, China. She got her $\mathrm{PhD}$ in human geography from Umeå University, Sweden. Currently she is mainly doing researches on agricultural development, GIS modeling, environmental risk assessment of pesticides, and remote sensing.

Jun Geng received the BS degree from Anhui Normal University, Wuhu, China, in 2009, the MS degree from Nanjing Forestry University, Nanjing, China, in 2012. He is currently working toward the PhD degree at Nanjing University, Nanjing, China. His research interests include remote sensing modeling and applications for vegetation ecosystem.

Lechan Yang is a PhD candidate in environmental remote sensing at School of Geographic and Oceanographic Sciences, Nanjing University, Nanjing, China. Her research focuses on the application of thermal infrared remote sensing and the application of geographic information system technology in agriculture disasters.

Shuhe Zhao received the $\mathrm{PhD}$ degree from Nanjing University, Nanjing, China, in 2003. He is currently an associate professor with the School of Geographic and Oceanographic Sciences, Nanjing University, Nanjing, China. His research interests include hyperspectral remote sensing, ecological remote sensing and global change, and application of pattern recognition methods in remote sensing.

Wenfeng Zhan received the $\mathrm{PhD}$ degree from the College of Resources Science and Technology, Beijing Normal University, Beijing, China, in 2012. He is currently an associate professor with the School of Geographic and Oceanographic Sciences, Nanjing University, Nanjing, China. His main research focuses on the urban heat island, thermal anisotropy, and disaggregation of land surface temperature.

Fei Wang is a PhD candidate in environmental remote sensing at School of Geographic and Oceanographic Sciences, Nanjing University, Nanjing, China. His main research focuses on disaggregation of land surface temperature and the application of thermal infrared remote sensing. 